\title{
EVALUATION OF ENDODONTIC TREATMENT IN THE PRACTICE OF THERAPEUTIC DENTISTRY
}

Received 11 October 2021;

Received in revised form 22 December 2021; Accepted 02 January 2022

\author{
Lyudmila Antonova $\mathbb{D}^{D}$, Islam Shekhiev $(\mathbb{D}$, \\ Marina Suvorova (D), Galina Emelina (D), \\ Anna Teplova ${ }^{\varpi}$ (1)
}

Penza State University, Penza, Russia

stomannavaleryevna@mail.ru

ABSTRACT - AIM OF THE STUDY is to study the need for a qualitative diagnosis before endodontic treatment, as well as methods for determining additional root canals, ways of passing the root system of the tooth, irrigation and obturation methods and the frequency of possible complications during endodontic treatment.

MATERIALS AND METHOD: The quality of endodontic treatment was studied using the social research method (questionnaire) among dentists from Penza and Penza Region (Russia). 140 practicing doctors participated in the study.

RESUlTS AND DisCusSion: According to the results of the survey, most doctors note a favorable result of endodontic treatment and associate this with the use of X-ray imaging, especially computed tomography, which greatly contributes to the qualitative and accurate mapping of the root system and the surrounding bone structure.

ConClusion: After the conducted research, we can assume that in the near future no intervention in the root system will be complete without preliminary $\mathrm{X}$-ray diagnosis and without means of magnification.

KEYWORDS - endodontic treatment, dentist, X-ray diagnosis, root canal.

\section{INTRODUCTION}

Endodontic treatment is a complex of manipulations, the purpose of which is to depulpate an infected tooth, giving a shape to the root canal based on the chosen obturation technique $[2,3,6,9]$.

Each stage of endodontic treatment requires special attention, knowledge and skills of the dentist, especially at the diagnostic stage [5,7]. It is precisely due to neglecting this stage that complications most often occur, therefore, it is important to identify the number of root canals, their shape, structure and all possible variations of the anatomical structure of the maxillary system, which is observed both on the upper and lower jaw [1, 8]. In 1971, Professor Walter Hess proved to the whole world the diversity and complex- ity of the morphology of root canals, which is difficult for full-fledged cleaning and obturation $[4,10,11]$.

Particular attention should be paid to the first molar of the upper jaw, because it is in this tooth that the number of root canals varies and can reach eight $[6,7,10]$.

Such a clinical case was described in 2011 by Kottor J. In Portugal, during endodontic treatment in a 30-year-old Indian patient, eight root canals were identified, namely: three root canals were identified in the mesial-buccal and distal-buccal roots, and two canals in the palatine root [5].

\section{MATERIALS AND METHODS}

The subjects of the study were dentists of Faculty of Dentistry at Penza State University, as well as dentists of Penza and the Penza region. 140 doctors took part in the study, of which 72 dentists have up to 5 years of work experience, 34 dentists - 5-10 years, 30 doctors - 11-15 years and 4 dentists - above 15 years. 108 doctors work at private institutions and 32 dentists - at public institutions.

The evaluation of the quality of endodontic treatment was carried out using a sociological research method (questionnaire). In the course of the work, 140 questionnaires consisting of 25 questions were filled out and processed, taking into account the specialist's work experience, diagnostic methods, treatment stages and materials used. Statistical processing of the received data was carried out using the Statistics 8.0 application software packages for Windows.

\section{RESULTS AND DISCUSSION}

According to the results of the survey, diagnostic $\mathrm{X}$-ray examination before the start of endodontic manipulations is carried out; always $-51 \%$ of doctors who took part in the survey, 33\% - often, $11 \%$ - rarely and only 5\% - never resort to this diagnostic method. They also use CT quite often in their practice, namely, $12 \%$ of doctors absolutely always conduct an X-ray examination for patients with 3D, $40 \%$ - quite often, $20 \%$ - rarely and, unfortunately, a considerable part, namely $28 \%$ - never use CT in their practice.

Accordingly, $70 \%$ of the surveyed doctors noted a positive result in endodontic treatment using $\mathrm{X}$-ray diagnosis. 
Additional methods of magnification (binoculars, microscope) are used in their practice by only 20 out of 140 interviewed doctors, even taking into account the fact that they significantly increase the quality of the manipulations performed.

Most of the practicing dentists, namely $93 \%$ (130 people) recorded the occurrence of additional root canals in their practice, and special attention was paid to the first molar on the upper jaw, where the root canal system is the most variable and unpredictable (Fig. 1, 2).
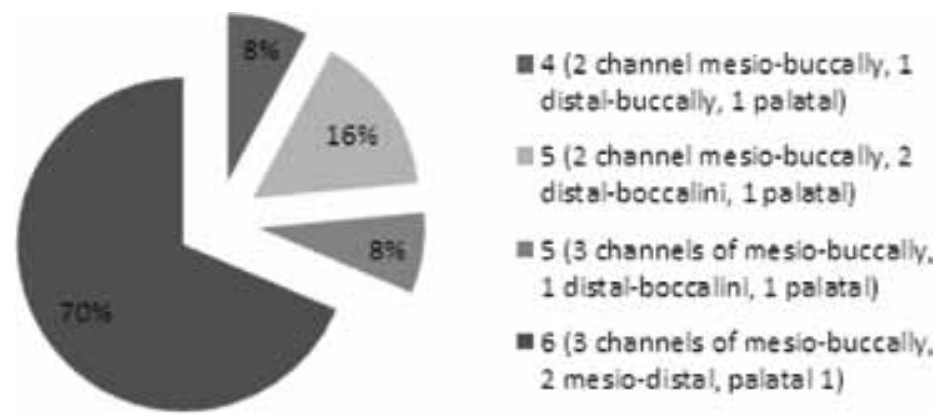

Fig. 1. Options for the location of root canals

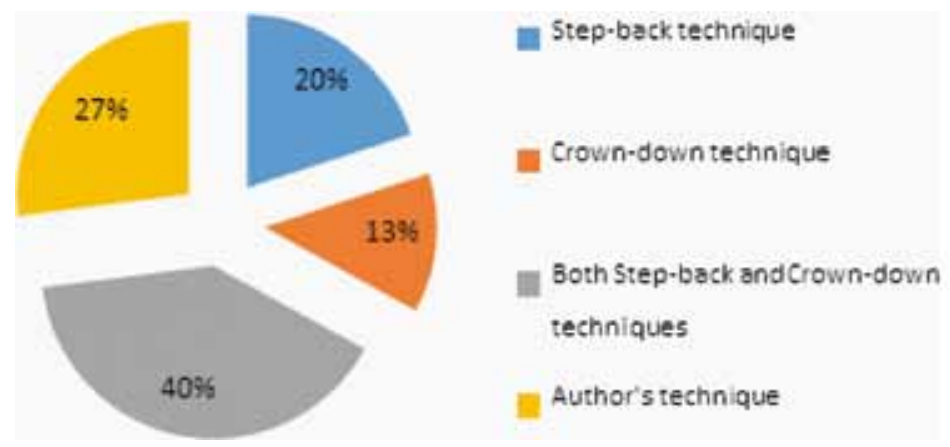

Fig. 2. Selection of the technique of instrumental treatment of root canals

The majority of the surveyed doctors - $84 \%$ use endodontic tips, which indicates the high technical equipment of doctors.

One of the aspects of high-quality endodontic treatment is the choice of a means for washing root canals. The results of the survey showed that sodium hypochlorite solution is mainly used (105 people - 75\%), which has the most pronounced antimicrobial effect, and $25 \%$ - a combination of solutions.

Drying of root canals is an equally important stage, if neglected, complications may arise, for example, the development of an air embolism when drying the canals with air. Questionnaire data showed that doctors make a choice in favor of paper pins $-67 \%$, cotton wool $-20 \%$ and the remaining $13 \%$ use a combination of the above-mentioned means.

The most commonly used material for obturation of root canals are preparations based on zinc oxide and eugenol $-71 \%$, zinc-phosphate + resorcinol formaldehyde $-6 \%$, materials based on epoxy resins $-15 \%$, resorcinol-formalin + zinc oxide eugenol - 8\%.

For obturation of the root canal system $95 \%$ of dentists use in my practice gutta-percha pins, which ensures a reliable seal, and only $5 \%$ disregard their use.

Questionnaire data showed that $90 \%$ of doctors perform root canal fillings up to the physiological apex, $5 \%$ - up to the anatomical apex, 5\% - are removed beyond the apex.

$\mathrm{X}$-ray diagnosis is an integral part of the work of any modern dentistry [1]. So, a large number of doctors in their practice widely use both extraoral research methods such as computed tomography, orthopantomography, and intraoral methods - sighting. Based on this, it was found that almost all doctors - 75\% always carry out a control scan to identify the quality of obturation, 20\% - often, 5\% - rarely.

Every practicing dentist has faced complications after the treatment. This is associated with a number of reasons, and the most common of them is the destruction of anatomical (physiological) narrowing, which was found in practice in $48 \%$ of the respondents, a missed root canal $-17 \%$, a fracture of the instrument in the root canal $-6 \%$, perforation of the root walls $-2 \%$, due to infection $-27 \%$.

The above reasons lead to complications such as changes in periapical tissues $57 \%$, residual pulpitis $10 \%$, post-sealing pain $-33 \%$.

In the structure of the reasons for the irregular use of additional diagnostic tools, the first place belongs to the problem of the lack of necessary equipment in clinics for X-ray diagnostics and the need to refer patients to specialized institutions. Further, there are a number of reasons for the lack of financial capabilities of patients, since conducting 3D diagnostics additionally requires costs. The third reason was the inability of the doctor to decipher and describe CT scans.

\section{CONCLUSION}

The results of the survey showed that carrying out diagnostic measures, such as $\mathrm{X}$-ray examination, during endodontic 
treatment significantly reduces the risk of complications, which is associated with the detailing of the root system on a CT scan and predicts a favorable outcome of the dentist's intervention. Also, 14\% of the respondents noted the high quality of treatment when using additional means of magnification, which contributes to better visualization of the working field. Based on the above, we can assume that in the near future no intervention in the root system will be complete without preliminary diagnosis on an X-ray machine and without means of magnification.

It was noted that sodium hypochlorite is the actual preparation for irrigation, and paper pins are the best way to dry the channels, as noted by most of the interviewed doctors, so we suggest using them in practice.

In the issue of obturation, more than $90 \%$ of dentists preferred gutta-percha pins and filling to the physiological tip, which indicates the relevance of using this method of filling and its effectiveness?

\section{REFERENCES}

1. AKHMEdova Z.R., VinnicheNKo YU.A., ARzhANTSEV A.P. Instrumental processing and X-ray examination of root canals of teeth. Miklos, 2010 $111 \mathrm{p}$.

2. Borovsky E.V. Therapeutic dentistry. - M. - 2006 $797 \mathrm{p}$.

3. KAZEKo, L.A. Methods of disinfection of root canals of teeth: textbook. - method. manual / L.A. Kazeko, I.N. Fedorova. Minsk : BSMU, 2009 - 40 p.

4. Lunitsyna, YU. V. Comparative evaluation of the effectiveness of various methods of filling root canals of teeth / Yu. V. Lunitsyna, I. E. Zubova // Problems of dentistry. - 2015. - No. 2. 9-12 p.

5. Chagai, A. A. The role of dental anatomy in planning and conducting endodontic treatment / A. A. Chagai, D. V. Cherkasov // Problems of dentistry. 2011. - No. $1.28-29$ p.

6. Plotino J. The third molar of the mandible with three mesial roots. Clinical case // Pharmgeocom inform. No. 4. $2011-26-27$ p.

7. KRITOFEN, J.R. Color atlas and text on endodontics / J.R. Kritofen. 2nd ed. Mosby-Wolfe, 1995. - p. 334.

8. Al Shalabi R.M., Omer O.E., Glennon J., JenNiNGS M., CLAFFY N.M. // Anatomy of root canals of the first and second permanent molars of the upper jaw. // International Scientific-practical conf. -2000. -3 (5). - pp. 405-14.

9. Emelina G. V., Suvorova M.N., Zyulkina L. A., KuZNetsova N.K., EMELina E. S. Evaluation of the prevalence of inflammatory processes in periodontal tissues in the Penza region. 2018. Journal of Pharmaceutical Sciences and Research. 10(4), pp. 973-975.
10. Ng Yu.L., Aung T.H., Alavi A., Gulabiwala K. Morphology of the root and canal of Burmese maxillary molars.//Int.Entod.J. - 2001. - No 34 (8). - pp. $620-30$.

11. Sevititov A.V., Enina Yu.I., Dorofeev A. E., KamensKov P. E., Kozhemov S.I., NikONOVA A.V. Investigation of the influence of various abrasive factors on the microrelief of the surface of hybrid ceramic orthopedic structures. Option. 2019. Volume 35. No. S24. p. 